\title{
Establishment of a highly efficient hematopoietic differentiation model from human embryonic stem cells for functional screening
}

\author{
PANG SuLei ${ }^{1}$, WU QingQing ${ }^{1}$, TIAN Sha ${ }^{2}$, SU Pei ${ }^{1}$, BAI Yang ${ }^{1}$, GAO Jie ${ }^{1}$, YANG YiQing ${ }^{1}$, \\ LIU Xin ${ }^{1}$, ZHU ZhengMao ${ }^{2}$, XU YuanFu ${ }^{1} \& \mathrm{ZHOU} \mathrm{JiaXi}^{1 *}$ \\ ${ }^{1}$ State Key Laboratory of Experimental Hematology, Institute of Hematology and Blood Diseases Hospital, Chinese Academy of Medical \\ Sciences and Peking Union Medical College, Tianjin 300020, China; \\ ${ }^{2}$ College of Life Sciences, Nankai University, Tianjin 300071, China
}

Received March 23, 2013; accepted July 4, 2013

Citation: Pang S L, Wu Q Q, Tian S, et al. Establishment of a highly efficient hematopoietic differentiation model from human embryonic stem cells for functional screening. Sci China Life Sci, 2013, 56: 1147-1149, doi: 10.1007/s11427-013-4567-0

Human embryonic stem cells (hESCs) have been successfully differentiated into hematopoietic progenitor cells with colony formation capacity and further into various kinds of blood cells including erythrocytes, megakaryocytes, neutrophils, nature killer cells and T lymphocytes [1-7]. Nevertheless, the differentiation efficiency is extremely low. The differentiation usually involves complex steps such as embryonic body formation or co-culture with stromal cells, causing inconsistencies and difficulties in dissection of its molecular mechanisms [8,9]. Therefore, it is essential to establish a well-defined hematopoietic differentiation model that is independent of serum and stromal cells and much easier to manipulate genes for functional screening, thus the underlying molecular mechanism of hematopoietic differentiation of hESCs could be dissected more easily.

In this study, to avoid inconsistencies caused by feeder cells and serum replacement in the culture medium, we maintained H1 hESCs on matrigel-coated plates in a chemically defined medium, mTeSR. For the initiation of differentiation, hESCs were re-plated as single cells in custom mTeSR medium with various concentrations of growth factors $\left(50 \mathrm{ng} \mathrm{mL} \mathrm{mL}^{-1} \mathrm{BMP}-4,50 \mathrm{ng} \mathrm{mL}^{-1}\right.$ Activin A, $40 \mathrm{ng} \mathrm{mL} \mathrm{m}^{-1}$

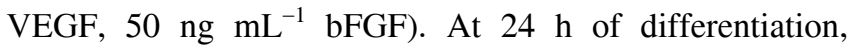
mRNA levels of mesoderm marker brachyury $(T)$ and MIXL1 were drastically up-regulated and maintained at a

*Corresponding author (email: zhoujx@ihcams.ac.cn) high level for a further $72 \mathrm{~h}$ (Figure1A). As shown by immunostaining, almost $100 \%$ of the cells were positive for brachyury (T) (Figure 1A). Generation of uniform mesodermal precursors facilitates further hematopoietic differentiation. Indeed, $\mathrm{CD} 34^{+} \mathrm{CD} 31^{+}$cells, which have been recognized as hematopoietic precursors derived from hESCs [10], emerged on day 4 of differentiation and constituted $\sim 25 \%$ of the cell population on day 6 (Figure 1B). The terminal differentiation potential of the derived hematopoietic progenitors was verified by generation of various types of colonies, including CFU-E (erythroid), CFU-M (macrophage), and CFU-GM (macrophage/granulocyte) (Figure 1B). Therefore, hematopoietic progenitors with terminal differentiation potential were successfully derived as monolayer independent of stromal cells and sera.

As mentioned above, the major advantage of differentiation as monolayer is greater accessibility for gene manipulation to facilitate mechanistic studies. To explore whether highly efficient RNA interference can be achieved in our monolayer differentiation model and further affect hematopoietic differentiation, we designed five shRNAs targeting the brachyury $(T)$ gene and tested their interference efficiencies. Strikingly, two shRNAs, T1093 and T2350, interfered with brachyury $(T)$ expression quite efficiently at both mRNA and protein levels (>90\%) (Figure 1C, data not shown). Furthermore, interference of brachyury ( $T$ ) expression severely impaired further hematopoietic differentiation. 

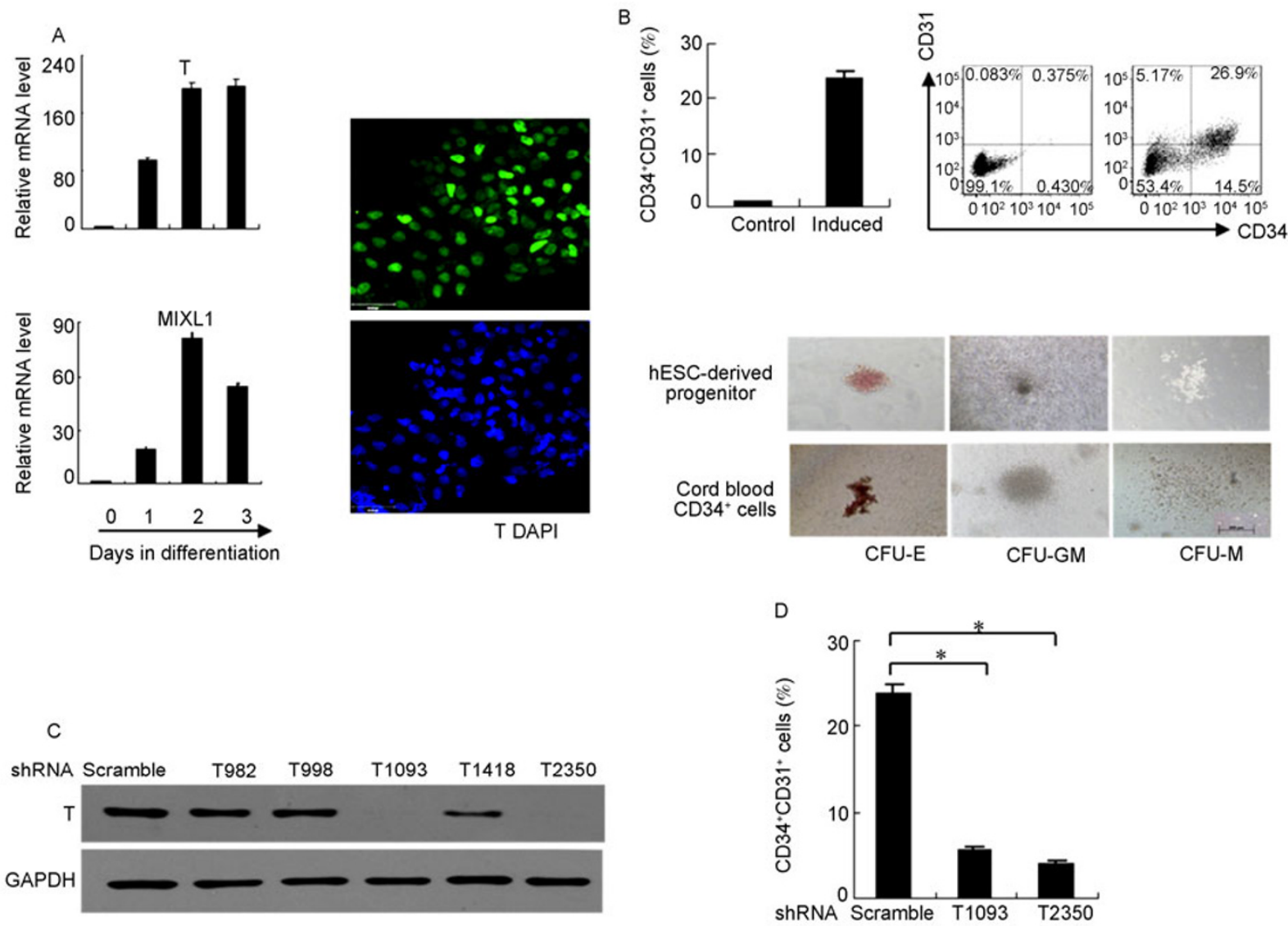

Figure 1 Efficient hematopoietic differentiation and RNA interference of human embryonic stem cells. A, mRNA levels of brachyury $(T)$ and $M I X L$ measured by real-time PCR and immunostaining of brachyury (T) after hematopoietic differentiation of hESCs. Scale bar, $59 \mu \mathrm{m}$. B, Hematopoietic differentiation of $\mathrm{H} 1 \mathrm{hESCs}$. The percentage of $\mathrm{CD} 34^{+} \mathrm{CD} 31^{+}$cells was measured by flow cytometry after $6 \mathrm{~d}$ of induction. Hematopoietic precursors were applied to colony formation assays. CFU-E, erythroid; CFU-M, macrophage; CFU-GM, macrophage/granulocyte. Scale bar, $200 \mu \mathrm{m}$. C, Western blotting of brachyury (T) protein after RNA interference with shRNAs. D, Percentage of $\mathrm{CD} 34^{+} \mathrm{CD} 31^{+}$cells measured by flow cytometry after RNA interference of brachyury $(\mathrm{T})(* P<0.05)$. All experiments were independently repeated three times.

Only $\sim 5 \% \mathrm{CD} 34^{+} \mathrm{CD} 31^{+}$cells were generated, which was much lower than that in the control group $(\sim 25 \%, P<0.05)$ (Figure 1D). After brachyury (T) interference, CD34 ${ }^{+}$cells were further sorted and applied to colony formation assays. Interestingly, we found that no colonies formed after two weeks of culture in medium containing methylcellulose (data not shown). These results suggested that hematopoietic precursors generated with brachyury $(T)$ interference lost their terminal differentiation potential. Taken together, our results show that this stepwise hematopoietic differentiation model in a monolayer can be used for highly efficient RNA interference. Recently, using small molecules, Wang et al. reported a three-step strategy to induce the differentiation of hESCs into hematopoietic progenitors. They demonstrated that retinoic acid and transforming growth factor- $\beta$ signaling pathways are important regulators in hematopoietic differentiation of hESCs [11,12]. These studies revealed important signaling pathways during hESC differentiation, but there are obvious limitations because only a limited number of chemical inhibitors are available to manipulate signaling pathways, which hinders functional screening at the single gene level. In our monolayer system, as indicated by efficient RNA interference of the brachyury $(T)$ gene, shRNA targeting of genes can be used for functional screening to identify important regulators of hematopoietic differentiation of hESCs. Our system should be able to facilitate functional screening and mechanistic dissection of human hematopoietic development.

This work was supported by the National Basic Research Program of China (2012CB966403), National Natural Science Foundation of China (31171431), and Tianjin Natural Science Foundation (11JCYBJC27300).

1 Kaufman D S, Hanson E T, Lewis R L, et al. Hematopoietic colony-forming cells derived from human embryonic stem cells. Proc Natl Acad Sci USA, 2001, 98: 10716-10721

2 Ma F, Ebihara Y, Umeda K, et al. Generation of functional erythrocytes from human embryonic stem cell-derived definitive hematopoiesis. Proc Natl Acad Sci USA, 2008, 105: 13087-13092

3 Lu S J, Feng Q, Park J S, et al. Biologic properties and enucleation of red blood cells from human embryonic stem cells. Blood, 2008, 112: 4475-4484

4 Takayama N, Eto K. In vitro generation of megakaryocytes and platelets from human embryonic stem cells and induced pluripotent 
stem cells. Methods Mol Biol, 2012, 788: 205-217

5 Choi K D, Vodyanik M A, Slukvin II. Generation of mature human myelomonocytic cells through expansion and differentiation of pluripotent stem cell-derived lin-CD $34^{+} \mathrm{CD} 43^{+} \mathrm{CD} 45^{+}$progenitors. J Clin Invest, 2009, 119: 2818-2829

6 Knorr D A, Kaufman D S. Pluripotent stem cell-derived natural killer cells for cancer therapy. Transl Res, 2010, 156: 147-154

7 Timmermans F, Velghe I, Vanwalleghem L, et al. Generation of T cells from human embryonic stem cell-derived hematopoietic zones. J Immunol, 2009, 182: 6879-6888

8 Kaufman D S. Toward clinical therapies using hematopoietic cells derived from human pluripotent stem cells. Blood, 2009, 114: 3513-3523

9 Moreno-Gimeno I, Ledran M H, Lako M. Hematopoietic differentia- tion from human ESCs as a model for developmental studies and future clinical translations. Invited review following the FEBS Anniversary Prize received on 5 July 2009 at the 34th FEBS Congress in Prague. FEBS J, 2010, 277: 5014-5025

10 Real P J, Ligero G, Ayllon V, et al. SCL/TAL1 regulates hematopoietic specification from human embryonic stem cells. Mol Ther, 2012, 20: 1443-1453

11 Yu C, Liu Y, Miao Z, et al. Retinoic acid enhances the generation of hematopoietic progenitors from human embryonic stem cell-derived hemato-vascular precursors. Blood, 2010, 116: 4786-4794

12 Wang C, Tang X, Sun X, et al. TGFbeta inhibition enhances the generation of hematopoietic progenitors from human ES cell-derived hemogenic endothelial cells using a stepwise strategy. Cell Res, 2012, 22: 194-207

Open Access This article is distributed under the terms of the Creative Commons Attribution License which permits any use, distribution, and reproduction in any medium, provided the original author(s) and source are credited. 